\title{
Coexisting Needs: Paradoxes in Collegial Reflection-The Development of a Pragmatic Method for Reflection
}

\author{
Marie Nilsson, Ingemar Andersson, and Kerstin Blomqvist \\ Department of Health and Society, Kristianstad University, 29188 Kristianstad, Sweden \\ Correspondence should be addressed to Marie Nilsson; marie.nilsson@hkr.se
}

Received 6 April 2017; Revised 24 June 2017; Accepted 17 August 2017; Published 28 September 2017

Academic Editor: Angelica Moè

Copyright (C) 2017 Marie Nilsson et al. This is an open access article distributed under the Creative Commons Attribution License, which permits unrestricted use, distribution, and reproduction in any medium, provided the original work is properly cited.

\begin{abstract}
This paper addresses a feasibility study of a method for recurrent collegial reflection. A qualitative approach, using a participatory research design, was adopted. The collegial reflection was implemented in a school, in a middle-sized municipality in southern Sweden, with 21 teachers participating in the intervention. Data collection included digital recordings of collegial reflection, open questions by mail, and individual interviews. Findings indicated one major theme, paradoxes in the design of the collegial reflection, and three categories: wanting to decide and wanting to be guided; meeting each other as teachers and/or as persons; and looking for the safe and/or looking for the new. Before implementing the method in another context, management needs to appreciate these contradictory experiences, allow for voluntary participation, address participants' expectations, and allocate time and tasks. This study implicates that collegial reflection may contribute to teachers' professional development, and it is thereby relevant to teachers' classroom practice and pupils' learning. We conclude that, by creating a structure which supports teachers' collegial reflection, the school may function as a supportive environment, which may contribute to teacher retention.
\end{abstract}

\section{Introduction}

In recent years, the psychosocial work environment for teachers has changed, internationally as well as in Sweden [1, 2]. Their work pace has been intensified, and teachers express needing more reflection time during their workday [3-5]. Collaborative reflection with colleagues, that is, collegial reflection, can be a way for managements to meet these changes and create a work environment that is supportive to the teachers' professional development [6]. This, in turn, has implications for their work situation, their teaching, and their pupils' learning development.

Since collegial reflection may take different forms, it is advisable to test it at the intended environment before implementing it comprehensively. A feasibility study makes it possible to identify methodological uncertainties of an intervention and to test how the participants experience it, in order to modify changes according to the study results before any larger scale intervention [7]. The research question was: "Is collegial reflection a way to meet teachers' need for more reflection time in order to develop professionally, and how can collegial reflection be designed to meet this need?"

\section{Literature Review}

Reflection is an important part of teachers' professional development $[3,8]$ and is considered as a prerequisite to recognize and change routines $[9,10]$. It is a concept that is often used in the educational context as well as within today's work science discourse [11, 12]. However, the frequent use of the concept has led to the paradoxical situation that it is often used in a nonreflected manner [13]. Reflection can be described as systematic thinking [14], emanating from an experience $[11,15]$, and it is usually depicted as leading to the testing of a hypothesis $[16,17]$. Consequently, it combines praxis and action with theory and sense-making in a dialectical process [18].

As a professional, one can reflect about what one does while doing it, that is, reflection in action, or as reflection on action, that is, after the action has been completed [10]. In order to use reflection as a means for workplace learning, "it is important to recognize [...] that the concept of reflection provides meaning at different levels - individual, group or collective and organization" $[19$, p. 29]. Reflection, individual as well as collaborative, is considered as a valuable means to 
professional development [20], and there are a number of concepts used to describe similar processes, for example, peer-to-peer exchange [21], professional dialogue [22], and peer coaching [8]. Previous empirical research has often focused on teacher education or teachers in their early years of the profession (e.g., $[23,24]$ ), while less is studied on teachers in general [20].

Collective reflection has been described in various ways. One example is technical reflection, which can be seen as an instrumental type of reflection, a response to problems without questioning the problem per se [25], and having ends not open to criticism [26]. It is a "technical response to specific situations without changing perspectives" [27, p. 250]. This type of reflection, however, has limited possibilities of changing work conditions in a more profound way. Another example of collective reflection is the dialogic reflection, which can be described as a way of "stepping back" from the actual event and considering different alternatives for explaining [25] and synthesizing new ideas [27]. Yet another type of reflection is critical reflection. The importance of critical reflection has been raised in order to meet the demands of flexibility that are pervasive in the contemporary workplace climate of society [28]. Critical reflection includes four steps of thinking: hunting assumptions; checking these assumptions; seeing things from different viewpoints; and taking informed action. In the first two steps, one tries to surface one's taken-for-granted assumptions and then assess how accurate and valid they are for one's actions [29]. The next step is a way to facilitate this process. By looking at the assumptions from different angles, these assumptions can be questioned. This leads to the last step, taking informed action. Critical reflection is thereby embedded in values and questions regarding power [29], and it is a fundamental element of work life as well as a democratic society at large [30].

In many Western countries, teachers' work situation is characterized by an increasing market orientation, efficiency demands, assessment of results, and demands on the individual to develop professionally [31]. With an increasing focus on teachers' professional development, the focus on collegial collaboration and dialogue has similarly grown [32]. The practice of collegial reflection entails both possible benefits and barriers. In a study about participation in a collaborative reflection group, teachers stated that their learning increased, both about their school and themselves [20]. Other rewards were highlighted in the same study, such as releasing of stress, having time to slow down, and experiencing that other teachers share similar feelings and they are not alone.

At the same time, there are important challenges to the participation in professional dialogue [22]. Limited time and access to peers is an important challenge [20]. Other challenges are insufficient structural and social supports, demands of immediate tasks $[33,34]$, and fear of being perceived as less competent or the contrary, too presumptuous, by one's colleagues [35].

Some essential features have been recognized when designing reflection among colleagues. Boud and Walker [36] suggested the context to be the single most important influence on reflection and learning. Issues to regard within the context are, for example, the comprehensive sociopolitical influence, the issue of building trust, and the question of power among the participants. Glazer et al. [20] also highlighted some core issues, such as designating a space and time for reflection on a regular basis and having an outside facilitator who guided the meetings. Other issues regarded having an agreement among the group members, ensuring their participation as well as respecting confidentiality, and, lastly, having a topic generation that is needs-based and emergent among the participants.

Hence, with this in mind, and based on a previous study in the involved municipality indicating the need for reflection time [37], we decided to conduct a feasibility study on collegial reflection. Even though the teachers experienced time shortage, they expressed a wish to introduce collegial reflection as part of their work. If brief, but recurrent, collegial reflection meetings would support the participating teachers' professional development, it would be worth further investigation. In this study, reflection is considered as a means to develop professionally by reflecting on work-related actions and experiences through a dialogue with colleagues. In addition, collegial reflection is seen as a way to structurally meet the changing psychosocial work environment and support the individual teachers to collectively find alternative ways to understand and meet these changes. The focus of this feasibility study was to look at the design of a weekly, 30-minutelong, collegial reflection model, in order to modify it and subsequently implement it in a larger scale.

\section{Aim}

The aim of the study was to explore teachers' experiences of collegial reflection as a means to support their professional development.

\section{Methodology and Methods}

The present inquiry rests on an epistemological viewpoint, which relies on the constructivist paradigm of believing in multiple realities. Epistemology also influences how participants are perceived in the research [38], and constructivism is often associated with "the participants' views of the situation being studied" [39, p. 8]. As we believe that knowledge is created in collaboration between the researcher and the participants, and the relevance of aiming to understand a phenomenon from the perspective of those experiencing it [40], a participatory research design was chosen. This paper addresses the feasibility of a method's design, while the effects of the collegial reflection, and the participatory action research process, are addressed in another paper (in progress).

Given that the aim was to explore the teachers' experiences of the method's design, a qualitative approach was chosen, using three methods for data collection: digital recordings of the reflection meetings; mailed open-ended questions; and individual interviews.

We assumed that an inquiry cannot occur within a value-free framework, and the researchers were hence an integral part of both the research process and product [41]. Assuming this stance, the research is not carried out in an 
epistemological vacuum, instead the research is affected by the context. Consequently, the contextual factors need to be taken into account.

4.1. Context. The intervention took place in a school, in a middle-sized municipality in the south of Sweden. The socioeconomic standard of the inhabitants is average, as it is not very high nor very low. The municipality includes schools situated in cities as well as in the countryside. The involved school lies in a town with approximately 20,000 inhabitants. Pupils attending the school go to preschool classes up to sixth grade.

A major reorganization within the municipality shortly before the intervention might have had importance for how the collegial reflection was experienced as concurrent events are likely to influence an intervention. This included a change of school districts and a redistribution of principals, causing profound changes in the teachers' everyday work environment. In addition, there was a thorough reconstruction of the school building in 2014, which meant that, at the time of the intervention, the teachers were actually working at a construction site. Moreover, a major educational drive, the "Mathematics Boost", was launched for the teachers at the time of the intervention. This further training of mathematic teachers led to an increased workload as well as reduced time for collegial meetings. Despite-or rather thanks to-the reduced time for collegial meetings among the teachers, the principal at the participating school decided to implement the intervention of collegial reflection. The principal concluded that it was in trying work situations, such as this, that reflection time was most needed.

4.2. Participants. In total, 21 teachers participated in the intervention, of which fifteen were female. The principal decided that all teachers at the school should participate in the intervention. However, it was voluntary to participate in the research. All teachers at the school decided to participate in the research. In order to allow each participant enough time to talk, the participants were divided into groups. These were based on what grade they taught, two groups with teachers from preschool classes up to third grade and one group with 4-6-grade teachers.

4.3. Design and Procedure of the Intervention. The intervention was based on a needs assessment from the same school as the intervention $[5,37]$, indicating the need for more collegial reflection. The need assessment also suggested six topics which were considered by the teachers as important issues for their well-being, and it was decided to use these topics in the collegial reflection.

In line with the participatory approach, the intervention was designed in collaboration between the participating school (the principal and a group of seven teachers), a project support group, and the researchers. The support group, consisting of representatives from the municipality, teachers from the selected school, and representatives from the involved university, acted as a dialogue partner to the researchers. By involving the participants, several advantages were sought. One such advantage was that the needs of the people concerned were made explicit [42], which avoided the assumption of needs that in reality were preconceived ideas from outsiders. Another advantage was the likelihood of a successful implementation of the intervention (Polanyi et al., 2005) [43]. Previous research has shown that the degree of participation relates to the achievement of intervention goals and less resistance [44], and consequently the aspiration was to include the participants as much as possible.

Before implementing the intervention, a meeting was held with all the teachers at the participating school. The objectives of this meeting were threefold: to inform about the plans; to inspire and motivate the teachers to participate in the intervention; and to establish the basic ethical values guiding the reflection meetings. During this meeting, the teachers were asked to prioritize among the six topics that were identified in the needs assessment. The topics were prioritized in the following order: social relationships with colleagues; recovery; documentation; delimitation within the professional role; finishing work assignments without stress; and delimitation between work and private lives. These topics could be used as a starting point for the collegial reflection or as an alternative; they had the possibility of choosing a topic of their own. Each topic could be reflected upon as long as the group felt the need.

Ethical values, regarding taking turns, showing respect, and not being judgmental, were both discussed and presented in written form at the meeting. Ethical issues, such as these, are central in collaborative dialogues [45].

Even though previous research has suggested the benefits of an outside facilitator [20], it was decided that the collegial reflection was to be held by the teachers themselves. The intention was to make the intervention sustainable and not dependent on the involvement of the researchers. Consequently, there was a joint responsibility for the process during the reflection meetings, meaning that each participant was responsible for keeping the meetings as intended, and no one was assigned as leader. During the same meeting, each participant received written material about the reflection process that was to be used during the collegial reflection, the ethical guidelines, and the questions to be used to aid the reflection process.

Previous research has indicated that designating time and space for collegial reflection on a regular basis is a core issue [20]. Due to the teachers' work intensification, the design of the intervention was determined on a pragmatic basis. Each reflection meeting was to take thirty minutes, no more and no less. We hypothesized that thirty minutes would be short enough, not to interfere too much with the ordinary work tasks, but also long enough to allow meaningful reflection. The teachers met once a week for a reflection meeting at the school. By meeting on a weekly basis, our supposition was that it would be possible to continue the dialogue from the previous week, if needed.

The reflection dialogue followed a wheel of reflection, that is, a preset structure in three phases (Figure 1). This reflection model was based on a modified version of Gibbs' Reflective Cycle [46] and was applied to give the participants a useful structure for their reflection process. Phase 1 began with one of teachers telling the others about a case and 


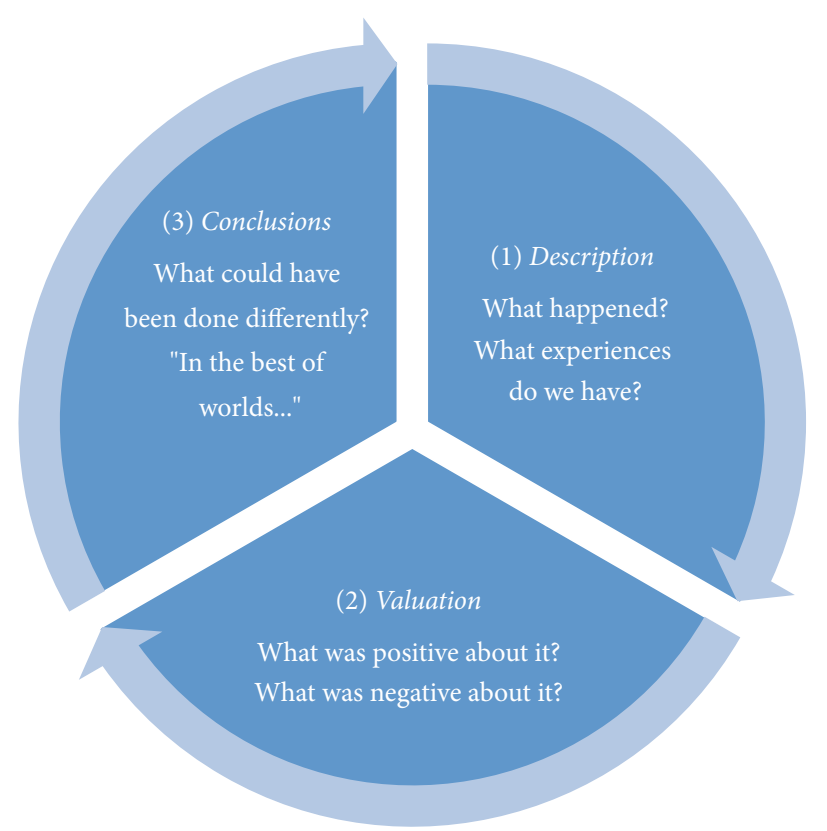

FIGURE 1: "The wheel of reflection," that is, the collegial reflection process.

included a description of it: "what happened?" Alternatively, they used the topic for a more general discussion: "what experience do we have?" In the next phase the participants evaluated the issue: "what was negative about it?" but also "what was positive about it?" In the third and final phase, the participants made conclusions from their dialogue: "what could have been done differently?," "in the best of worlds...." Phase 1 and the negative evaluation in phase 2 were to take at the most one meeting, to avoid dwelling too much on the negative aspects of the issue. The positive valuation and phase 3 could take as long as necessary. There was a strong emphasis on keeping the reflection meeting as constructive and positive as possible, that is, stressing things that actually work, but also focusing on creative ideas in relation to things that do not work.

Two months into the intervention, a follow-up meeting took place. At this meeting, the design and the process of the intervention were discussed, and uncertainties were ventilated. Ethical issues were once more discussed.

4.4. Data Generation. Data was generated by means of three methods: digital recordings of the reflection meetings; mailed surveys; and individual interviews. These methods were chosen in collaboration between the researchers, the principal, and the project support group, including some teachers from the school. All three methods were used in the result.

A total of 42 meetings were held in September-December 2014, divided equally between the three groups. All meetings were digitally recorded except on 6 occasions, when the recording failed due to technical problems. The missing recordings occurred randomly in all three groups. The reason for recording the meetings was to get an insight into the reflection process and also to get a group perspective on the collegial reflection.

In addition, six open-ended questions were mailed to the participating teachers on three occasions during the fall of 2014. The intention by using this method was to get an individual perspective on the collegial reflection while still being in the process of it. In all, 31 surveys were completed, of 63 possible ones. The same six questions were included on all three occasions. Examples of these questions were: What do you think about the design of the reflection meetings? Do you have any suggestions how to improve them?

Six months after the first reflection meeting, individual interviews were conducted, with the aim of gaining an individual perspective on the intervention after it was completed. All participating teachers were asked to participate. Three female teachers, each representing one of the three groups, took part. The interviews took place at the school, lasted for one hour each, and were digitally recorded. Examples of interview questions were: What is your opinion about the reflection meetings? What do you think about the allocation of 30 minutes per week for collegial reflection?

4.5. Data Analysis. Thematic analysis was used "for identifying, analyzing, and reporting patterns (themes) within data" [47, p. 79]. Since this current method for collegial reflection has not been studied before, an inductive approach was used in the analysis [40]. The collection and analysis of data were conducted concurrently. This method was chosen by the researchers as it is a suitable method for analyzing qualitative data on people's experiences and understandings of phenomena in particular contexts [48].

In the first phase, we familiarized ourselves with the data, reading and rereading the transcribed material, in order to get 
TABLE 1: Data extract, with codes applied, and subcategory.

\begin{tabular}{|c|c|c|}
\hline Data extract & Coded for & Subcategory \\
\hline $\begin{array}{l}\text { Because we hardly ever talk about the personal } \\
\text { stuff... [...] and I believe it to be quite important really, } \\
\text { to know your... you don't have to know them a lot, but } \\
\text { a little, I think. (Interview 2) }\end{array}$ & $\begin{array}{l}\text { Not talking about personal issues, which is } \\
\text { important }\end{array}$ & The private \\
\hline $\begin{array}{l}\text { Together, we could then discuss, for example, the new } \\
\text { action plans and such, and that was good. (Interview 2) }\end{array}$ & $\begin{array}{l}\text { The new action plans can be discussed with } \\
\text { colleagues }\end{array}$ & The professional \\
\hline
\end{tabular}

TABLe 2: Analytical process and findings.

Theme

Paradoxes in the design of collegial reflection

Category

Wanting to decide and wanting to be guided

Meeting each other as teachers and/or persons
Looking for the safe and/or looking for the new

Subcategories

Autonomous/governed

Integrating/segmenting

The professional/the private
Wanting to be with friends/wanting to make new acquaintances

Subject or grade groups/mixed groups a sense of the whole. In the second phase, the generating of initial codes was done manually, by highlighting and writing notes on relevant texts. This is a way of organizing the data into meaningful groups, without making interpretations. The next phase included arranging the different codes into categories and subsequently into themes (Table 1). A theme answers the research question, often at an abstract level [40]. In the two following phases, we checked if the categories and the themes worked in relationship to the entire data and created a thematic map (Table 2). Subsequently, the themes were defined and named. The final phase comprised the actual writing, selecting extracts, and producing a report and was part of the analysis [40]. The analysis process comprised both a descriptive part and an interpretative part, with the latter being more prominent in the second half of the analysis. All data were treated similarly regardless if it came from digital recordings, surveys, or interviews.

4.6. Ethical Considerations. Collegial reflection may involve certain risks for the involved participants. During the reflection meetings the teachers revealed experiences as well as opinions and values, and this could open up to vulnerability. However, since each participant decided how much he/she wanted to reveal, we estimated the benefits to outweigh the risk. Another possible risk was that the reflection meetings added to an already stressful work situation.

Both written and oral information about the study and the recording of the reflection meetings were given to the participating teachers. The participants signed an informed consent form before starting the collegial reflection. All data has been treated confidentially, and measures have been taken to ensure the anonymity of the participants. The study was conducted in agreement with the Swedish Law of Research Ethics, SFS 2003:460. This law is in line with the ethical guidelines of the Helsinki Declaration [49].

\section{Findings}

The analysis identified one major theme, paradoxes in the design of the collegial reflection, and three categories: wanting to decide and wanting to be guided; meeting each other as teachers and/or as persons; and looking for the safe and/or looking for the new.

Paradoxes in the design of the collegial reflection meant that the teachers expressed feelings and experiences that were often contradictory. These paradoxes were sometimes found in the same teacher but most often found at a group level. The participants expressed two parallel experiences that the collegial reflection was both appreciated and depreciated. Some teachers were motivated to participate and saw it as something positive.

What I feel during our reflection meetings, is that they give us the opportunity to sit in peace and quiet and discuss things that are important, and we have the chance to come up with solutions. (group 1, second mail survey)

Others were more hesitant about the reflection meetings and expressed a need to use the time for other purposes. They experienced it as something other than their work, and it increased their stress.

Mostly it feels like an extra stress, since because we're doing the Mathematics Boost, there is hardly any time for planning. (group 1, first mail survey)

I would have needed that time in order to have time to do my work. (group 1, second mail survey)

5.1. Wanting to Decide and Wanting to Be Guided. The findings indicate a paradox, consisting of both wanting to be autonomous and make one's own decisions and wanting to be 
governed and guided by others. The freedom to make choices, and the responsibility it implies, is an inherent paradox. On the one hand, there is a desire not to have to make decisions and to be given instructions on what to do. On the other hand, there is a desire to be autonomous and be able to choose what to do. This ambivalence was noticeable in several ways in the data. One example is the issue of scheduling the reflection meetings. Being used to taking responsibility in their profession, the teachers were given the possibility of choosing within each group the time and day for their meetings. This issue turned out to be the one thing that created the most annoyance among the teachers. While some of the teacher viewed this option as an expression for their autonomy, some of the teachers considered it as a problem and expressed a preference for having been told what time the meetings should take place. They did not want to decide themselves but leave it in the hands of the principal. In this case, they preferred to be governed instead of given the responsibility.

It [the time for the meeting] should absolutely have been decided before the schedule was made, that it's 1616:30 or 14-14:30, or it doesn't matter. It has been the main point of frustration in all groups, that "Oh but I don't have the time now, and it doesn't suit me"... So, it has caused great frustration, nothing to do with [the reflection as such]. So we all think it's great once we are there. But it has been scheduled for awkward times as we had to schedule it between us, and that's not always a good thing. (Interview 2)

Another issue of ambivalence was the topics for the reflection meetings. Prior to the intervention, the teachers made a priority list of topics to be used as a support for the reflection. It was also possible to reflect on something completely different, an actual situation or a problem that any of the teachers had experienced. While some of the teachers appreciated the possibility of following the topic list, others felt restricted by it. Hence, some teachers wanted the freedom to make the choice themselves, and others wanted to be told what to reflect upon.

I feel that each one of us should contemplate whether we have something we wish to discuss. I don't think we should be controlled like that. I think it should be coming from ourselves. (group 2, digital recording)

Sometimes, some of us have felt frustration that we don't know what we are supposed to talk about. We are so goal oriented. (Interview 3 )

5.2. Meeting Each Other as Teachers and/or as Persons. Another paradox was linked to the actual purpose of the reflection meetings: whether they were meeting as professionals or as private persons. Some teachers expressed the need to meet as teachers, to exchange work-related ideas and discuss work-related issues. They considered the reflection meetings a way to develop as a teacher and improve their work situation.

When we are sitting discussing, we may come up with ideas on how to do things at the school, and that is positive, so there is an element of development in it. [...] You may have your mind set on something, and then the others come up with a different angle, and then you can sort of re-evaluate yours... whatever you felt earlier. (Interview 1)

- I have found these meetings really nice, to sit like this and just talk.

- Mmm.

- And you have the time and... I mean, like now, when we discuss the curriculum, things you don't have time to talk about otherwise, and I think that is positive.

- But one would want it to lead to a result

- Yes

- Maybe it will eventually. (group 1, digital recording)

Others expressed a desire to get to know each other better as individuals and not only as professional teachers. They anticipated the meetings to include personal aspects, thereby getting to know each other in a broader sense than merely as professionals. These teachers were more inclined to integrate their private lives with their professional lives, whereas the others preferred segmenting the two spheres. With an increased workload and intensified workday, there is less time for socializing and talking about issues that are not work-related, and they appreciated this opportunity, that was offered by the reflection session. They even stated that these meetings were the only times when they could socialize in a more relaxed way.

- I consider these meetings as a nice time and an opportunity to talk to my colleagues.

- It's just a pity that they need to be scheduled.

- Yes, it's a pity.

- On the other hand, we wouldn't have done it otherwise.

- No, that's what I'm saying, it's a pity that it has to be like that. (group 1, digital recording)

The discussions give insight into other people's everyday life, with worries and happy things. It also gives a great sense of belonging among us at the school. (group 1, second mail survey)

5.3. Looking for the Safe and/or Looking for the New. An issue, causing contradictory feelings within the groups but sometimes even within the same teacher, was the constellation of the groups. While some stated that they wanted to form the groups according to teaching of similar age groups or subjects, others preferred to mix the groups completely. One advantage of being in a more homogeneous group was that it gave an opportunity to be more specific in their reflections. They could speak about class-related or subject-related issues and thereby work with common issues in this forum. This view had connections to the former paradox that of meeting each other as a teacher or as a person. Many of the teachers, arguing for meeting each other as professionals, valued the opportunity that the homogeneous group offered. 
If the groups had been more linked to the respective pupils' ages, it could be more like collegial learning and how we can improve our teaching based on research, and work with pupils with special needs. (group 1, third mail survey)

Being in the homogeneous groups was also described as a way to be with friends, with whom they felt safe. Instead, the teachers who advocated heterogeneous groups valued the possibility of getting to know their colleagues better, people they would otherwise not talk to very much. They saw the reflection meetings as a way to learn more about other colleagues and make new acquaintances. They stated that they often chose the comfortable way and sat with close colleagues in the staff's room and saw the meetings as an opportunity to widen their circles.

I have missed the possibility to sit in peace and quiet and discuss with colleagues I otherwise don't see much of. It has been very positive. (group 1 , first mail survey)

The structure of the group has meant more and new ways of thinking, not only the usual with the closest colleague. (group 1, third mail survey)

I think that I am now more inclined to have discussions with more people outside my work team. (group 2, first mail survey)

These contradictory views, sometimes even expressed by the same teacher, can be interpreted as ambivalence between choosing what is familiar and safe, and the desire to expand.

\section{Discussion}

This paper addresses a feasibility study on collegial reflection, with the aim of identifying methodological uncertainties regarding its design and also to test how the participating teachers experienced it. The design of the collegial reflection emanated from a pragmatic perspective: the teachers expressed a need for reflection but simultaneously experienced being pressed for time. The question was: how can we design an intervention to make it possible for the teachers to reflect together? With this point of departure, it was decided to do a tradeoff, that is, to limit collegial reflection to thirty minutes but in return include it every week. This can be seen as a way of adapting to the work intensification and "the new era of teacher professionalism" [45, p. 430], which influences the managerial perspective on effectiveness and measurement of results. If the participating teachers experienced it as meaningful, it may also be a useful design for other workplaces and different contexts, since time shortage is prevalent in many professions.

The findings of the teachers' perceptions of the intervention indicated three paradoxes. At first glance, these paradoxes may seem like contradictions, but they are in fact coexisting. The paradoxes were found at both an individual level and a group level. Often, the paradoxes were parallel and differed in value from time to time. To find these coexisting perceptions is perhaps not surprising at a group level, although it is important to deal with when implementing collegial reflection. However, they sometimes also appeared within the same individual. This ambiguity should not be considered as a weakness, but a natural part of the flexible character of reflection as well as being human. Nonetheless, the ambiguity of the parallel experiences needs to be acknowledged and addressed in order to obtain the necessary motivation and trust among the participants.

The findings indicated that the reflection process included an exchange of perspective among the group members and at times also a reevaluation of one's original perspective. This can be interpreted as a dialogic reflection, since the participants considered different perspectives and searched alternative ways to solve problems [45]. Through dialogic and collaborative discussions of school issues, the participants were giving each other support, which has been found in other studies as well (e.g., [50]). As Brookfield [51] states, sharing experiences with colleagues, but also challenging each other's assumptions, is a way to give support.

The findings illuminated relevant aspects regarding the design of the collegial reflection such as designating time, adopting a participatory approach, and emphasizing ethical values. The need to designate time for the collegial reflection seemed to be accepted by the teachers, given that they have a time-pressed work situation. However, opinions differed regarding when this scheduled time should occur. Since the issue of deciding themselves the time for the meetings seemed to cause problems within the groups, we suggest that this should be decided by the principal. Previous studies have indicated the importance of designated time (e.g., [20]) and can be seen as a way to offer structural support and a supportive work environment. The design of the collegial reflection also included organizing the reflection groups according to similar grades, which caused ambivalent feelings among the participants. Even though previous research has indicated that such groupings are important to teacher learning [5254], the findings from this study indicate that both types of grouping, that is, mixed or according to grades/subjects, are experienced to lead to learning and professional development.

Regarding the participatory approach, the findings indicated that the element of being involved in the decision process was not appreciated by all teachers, which can be illustrated by the paradox of wanting to decide and wanting to be guided. It is the paradoxical relationship between, on the one hand, wanting the responsibility and, on the other hand, not wanting it. Bauman [55] used the concepts of freedom and safety to describe this paradoxical relationship. There is a value in each of them, but in exchange for more freedom, one inevitably loses some safety, and vice versa. One cannot have full control over the decision-making while at the same time experiencing the safety of being guided by someone else. An example of this paradox regarded the topics for the reflection. In line with the participatory approach, the teachers were involved in the topic generation for the collegial reflection. Six topics were previously identified in a need assessment conducted in the same school $[5,37]$, and consequently the topics emanated from the teachers themselves. These topics, prioritized in relevance by the teachers, were offered to guide the collegial reflection. Alternatively, the participants could 
choose a topic of their own. Previous research on collegial reflection has shown that topic generation should be needbased and emergent from the teachers themselves [20]. The findings of this study support this previous research, but it also highlights an ambivalence regarding whether the topics should be predetermined or generated during the actual reflection process.

As part of the participatory design, the project support group, the principal, and a group of teachers were involved in the design and implementation process. However, not all teachers at the school were involved in this process, and this has previously been a criticism of participatory approaches [56]. In order to obtain the benefits of participation, all participants need to be part of this process [57]. Consequently, we conclude that the implementation of the collegial reflection would have benefited by an increased participation by the teachers.

Ethical values, underpinning the reflection meetings, were discussed prior to as well as during the implementation of the intervention. The issue of respect was manifested in both contributing actively and listening to one's colleagues. Respect was also demonstrated through honoring confidentiality within the reflection group. This was seen as a way to create trust among the teachers. Previous research has shown that taking turns and being prepared to listen are important elements in the process of collaborative dialogue [45], and the issue of trust is an important part of collegial reflection [20].

Furthermore, the findings indicated divergent experiences among the participants regarding the purpose of the collegial reflection. While all teachers seemed to value the possibility of reflecting together on professional issues, some of them also wanted to include the more private sphere. The focus on professional matters supports their professional development which in turn would affect the students' learning [58]. By including the private sphere, the teachers come to know each other better, which enhances their feeling of safety. Feeling safe among colleagues contributes to employees' motivation to work [59], which is relevant in relation to teachers' retention in the profession. We suggest that collegial reflection should start with focusing on the professional role, and in time, if the group members agree to it, the private issues may be included.

The findings indicated that the collegial reflection leads to getting to know one's colleagues better and acquiring a sense of belonging with them. They were sharing experiences and offering each other social support. Social support from colleagues is a known health promoting resource [60-62], and as was highlighted by Glazer et al. [20], the feeling of not being alone in one's feeling is a powerful reward in collegial reflection. In addition, the participating teachers described the collegial reflection as a forum where they could "sit in peace and quiet." It seems as though the collegial reflection was an occasion when the teachers could unwind. Similar results have been found in previous research, suggesting that collegial reflection could release stress [20], and since stress is considered as an important risk factor for teachers' wellbeing, it is a relevant aspect.

However, not all participants considered the implemented collegial reflection as a good way to utilize time.
The findings showed that some teachers felt they would have needed the allocated time for other tasks instead and even indicated that the reflection meetings were not considered as part of their work. The demands of immediate and multiple tasks have previously been found to constrain professional dialogues among teachers [33,34], and conflicting priorities [63], such as implementing the intervention at the same time as the educational drive, may be a hinder. Similarly, limited time has previously been identified as an important barrier for collegial reflection $[20,64]$. In addition, previous research also indicated that high job demands have a hindering effect on participation in interventions [65]. Consequently, the findings of this study seem to support previous results, suggesting that other work tasks may have a hindering influence on teachers' attitude towards participating in collegial reflection. This highlights the importance that management needs to address the teachers' work load and support them in prioritizing among their tasks when implementing a new work element, such as collegial reflection.

In the postmodern era, teachers are faced with rapid changes, and this requires flexibility and adaptation to the marketization of education [66], as well as putting pressure on their professional development. As part of a work context, teachers need to make "sense of one's work" [67, p. 194] and comprehend what is happening. Collegial reflection could be one way to meet these requirements and to, collaboratively with colleagues, make sense of one's work. Collegial reflection would thereby be a resource for the teachers' professional learning and development. It is generally assumed that teachers' professional development improves classroom performance [68] and pupils' achievement $[69,70]$, making the collegial reflection of relevance not only for the teachers themselves, but also for their pupils. As the teachers' professional development is related to their teaching practice, it would also be of relevance for the quality of education. In addition, by creating a supportive environment, teachers' motivation to stay in the profession increases [71], which is of great importance.

\section{Methodological Considerations}

When the teachers were asked to participate in the intervention, everyone agreed and signed the informed consent form. Their participation in the intervention was not optional, since it was the principal's decision that all teachers should participate. However, it was voluntary to take part in the research. Had any of the teachers declined, there would not have been any digital recording of the meetings. Admittedly, their choice to participate may have been influenced by the choices of their colleagues. Nonetheless, since each teacher could decline to participate, and no one would have to know about it, we concluded that the principle of voluntariness was met.

Whether the intervention was conducted in a participatory manner may, however, be questioned. Stoecker [72] describes different forms of participatory research and discusses the issues of power and control. In the presented intervention, some-but not all-teachers participated in defining the original research questions and methods for 
making the needs assessment. All teachers were involved in prioritizing the reflection issues in the intervention. Yet, the teachers had to comply with the principal's decision to implement the intervention. Teachers who had not been part of the needs assessment in the previous research studies may have had the feeling that the intervention was initiated by the researcher and/or the principal-in any case an authority-and this could have generated resistance from them. As to the power relation between the teachers and the researcher, the latter made much of the initial decisions about the structure of the reflection meetings. However, two months into the implementation, this structure was modified according to the teachers' wishes and needs. Using Stoecker's [72] terminology, the research was collaborative, as both the researcher and the teachers contributed their knowledge and decided on the design of the intervention. Yet, to be truly participatory research, the teachers could have been more active in the research process. Still, knowing that time is a scarcity for teachers, it was difficult to accomplish this in practice. Consequently, the power over the intervention can be said to be divided between the teachers, the principal, and the researcher. Nonetheless, one result of the design was that the intervention continued even after the researcher withdrew from the research project. This indicates that the participants were not dependent on the researcher's presence [72], which can be considered a strength with the design.

A potential risk in choosing a particular method for reflection lies in becoming reified and simplified to just another technique. It runs the risk of missing the exploratory element of reflection and limiting its potential [73]. Too much formalization may also provoke resistance among the participants [74]. However, by being attentive to the process and modifying and changing its design according to the participants' opinions, we aimed at keeping the generative and flexible character of reflection, as well as the participatory approach.

In order to discuss the study's trustworthiness, the concepts suggested by Lincoln and Guba [75], credibility, dependability, confirmability, and transferability, have been used. Three different methods were used for data collection as a way to strengthen the study's credibility. Even though participation in the mailed open questions as well as the interviews was limited, the use of data triangulation is a strength of the study. While the mail survey and the interviews added an individual perspective on the intervention, the digital recordings contributed with a groups' perspective on it.

In order to strengthen the credibility of the results, they were discussed with the participating teachers at a meeting a few months into the implementation. The results were also confirmed by participating teachers in the project support group. Dependability was enhanced by using the same mail questions and interview questions for all participants and also by repeated discussions with other researchers. By presenting quotes to illustrate the analysis, we aimed to strengthen confirmability, just like being several researchers analyzing the material.

A relevant question regards transferability: whether this method is applicable to other contexts, both within the school context and to other professional groups. The aim of this study was to explore the participating teachers' experiences regarding this method. Since the contextual prerequisites are unique for this school, we conclude that, in order to transfer the results, they need to be recontextualized. Having done that, we believe it is applicable to other contexts.

\section{Implications and Conclusions}

In summary, this feasibility study presents a method for integrating collegial reflection in teachers' ordinary work and thus create a structure that functions as a supportive environment. By implementing collegial reflection, the teachers are given an opportunity to surface work-related issues and make experiences, thoughts, and feelings explicit. Through the dialogue with colleagues, the collegial reflection becomes a part of the teachers' professional development, which has important implications for their teaching practice. This, in turn, has the potential to lead to changes in pupil achievement and development. Consequently, it has implications for the quality of education. This highlights the importance of acknowledging the relevance of collegial reflection not only for school managements but also among school educators. By raising the awareness of its potential benefits and advocating its implementation in schools, the chances for it to be implemented increase.

This study provides knowledge on how a particular method for collegial reflection was experienced by the participants and thereby contributes with knowledge on how it can be designed according to the needs of the teachers themselves. It suggests that great efforts should be made to include all participants in the planning and the implementation and that the participation should be as thorough as possible. It also suggests that participation should be voluntary, in order to avoid resistance from the participants.

As part of the structure, it highlights the importance of allocating both time and space for the collegial reflection and suggests that management should present a set time for it and not leave the timing up to the groups themselves. It also points to the importance of supporting the teachers with regard to prioritizing among work tasks, when introducing collegial reflection as an additional task. Furthermore, it points to the importance of appreciating the parallel experiences of the participating teachers, for example, regarding the purpose of the collegial reflection, as well as its leading to the adding of stress or the release of it.

The intervention context has an impact on how the collegial reflection is perceived. In order to use this method in other places and among other professions, it needs to be recontextualized.

In conclusion, it is important to acknowledge the potential barriers to collegial reflection, but equally important to appreciate the possibilities it entails, as a way to support teachers' professional development and as a salutogenic resource in a supportive environment.

\section{Conflicts of Interest}

The authors declared no potential conflicts of interest with respect to the research, authorship, and/or publication of this article. 


\section{References}

[1] I. Arvidsson, J. G. Simonsen, C. Dahlqvist et al., Work Environment and Health among Teachers in 9-Year Compulsory School, Arbets- och miljömedicin, Lund, Sweden, 2013.

[2] A. Konu, E. Viitanen, and T. Lintonen, "Teachers' wellbeing and perceptions of leadership practices," International Journal of Workplace Health Management, vol. 3, no. 1, pp. 44-57, 2010.

[3] C. Day, M. Hadfield, and M. Kellow, "Schools as learning communities: Building capacity through network learning," Education 3-13, vol. 30, no. 3, pp. 19-22, 2002.

[4] A. Hargreaves, Changing Teachers, Changing Times, Studentlitteratur, Lund, Sweden, 1998.

[5] M. Nilsson, "Salutogenic and pathogenic aspects in relation to everyday well-being among teachers," Tech. Rep., Kristianstad University, 2012.

[6] M. Clement and R. Vandenberghe, “Teachers' professional development: A solitary or collegial (ad)venture?" Teaching and Teacher Education, vol. 16, no. 1, pp. 81-101, 2000.

[7] D. A. Richards, "The complex interventions framework," in omplex Interventions in Health. An overview of research methods, D. A. Richards and I. Rahm Hallberg, Eds., Routledge, 2015.

[8] C. Rhodes and S. Beneicke, "Coaching, mentoring and peernetworking: Challenges for the management of teacher professional development in schools," Journal of in-service education, vol. 28, no. 2, pp. 297-310, 2002.

[9] K. Kwakman, "Factors affecting teachers' participation in professional learning activities," Teaching and Teacher Education, vol. 19, no. 2, pp. 149-170, 2003.

[10] D. Schön, The Reflective Practitioner: How Professionals Think in Action, Basic Books, 1987.

[11] P. Emsheimer, "Reflection theories," in The elusive reflection, $\mathrm{P}$. Emsheimer, H. Hansson, and T. Koppfeldt, Eds., Studentlitteratur, Lund, Sweden, 2005.

[12] T. Ghaye, Teaching and Learning through Reflective Practice: A Practical Guide for Positive Action, Routledge, 2010.

[13] J. Bengtsson, "What is reflection?" in Reflection and practice within the teaching profession, C. Brusling G and G. Strömqvist, Eds., Studentlitteratur, Lund, Sweden, 2007.

[14] C. Rodgers, "Defining reflection: Another look at John Dewey and reflective thinking," Teachers College Record, vol. 104, no. 4, pp. 842-866, 2002.

[15] E. Cederwald, Reflection and self-understanding in "the communicative pedagogy", Lund University, 2006.

[16] J. Dewey, How we think: a restatement of the relation of reflective thinking to the educational process, Heath, Lexington, MA, USA, 1933.

[17] K. Lewin, Resolving social conflicts, American Psychological Association, Washington, DC, USA, 1948.

[18] P. Hoffman-Kipp, A. J. Artiles, and L. López-Torres, "Beyond reflection: teacher learning as praxis," Theory into Practice, vol. 42, no. 3, pp. 248-254, 2003.

[19] S. H, B. Elkjaer, and S. Höyrup, "Reflection: Taking it beyond the individual," in Productive reflection at work: Learning for changing organizations, C. Boud, P. Cressey, and P. Docherty, Eds., Routledge, New York, NY, USA, 2006.

[20] C. Glazer, L. Abbott, and J. Harris, "A teacher-developed process for collaborative professional reflection," Reflective Practice, vol. 5, no. 1, pp. 33-46, 2004.
[21] S. Rocco, "Making reflection public: Using interactive online discussion board to enhance student learning," Reflective Practice, vol. 11, no. 3, pp. 307-317, 2010.

[22] G. R. Daniel, G. Auhl, and W. Hastings, "Collaborative feedback and reflection for professional growth: preparing first-year preservice teachers for participation in the community of practice," Asia-Pacific Journal of Teacher Education, vol. 41, no. 2, pp. 159172, 2013.

[23] J. K. Harrison, T. Lawson, and A. Wortley, "Mentoring the beginning teacher: developing professional autonomy through critical reflection on practice," Reflective Practice, vol. 6, no. 3, pp. 419-441, 2005.

[24] J. K. Jay and K. L. Johnson, "Capturing complexity: A typology of reflective practice for teacher education," Teaching and Teacher Education, vol. 18, no. 1, pp. 73-85, 2002.

[25] N. Hatton and D. Smith, "Reflection in Teacher Education: Towards Definition and Implementation," Teahing \& Teacher Education, vol. 11, no. 1, pp. 33-49, 1994.

[26] M. Van Manen, "Linking Ways of Knowing with Ways of Being Practical," Curriculum Inquiry, vol. 6, no. 3, pp. 205-228, 1977.

[27] J. R. Ward and S. S. McCotter, "Reflection as a visible outcome for preservice teachers," Teaching and Teacher Education, vol. 20, no. 3, pp. 243-257, 2004.

[28] J. Fook, V. Collington, F. Ross, G. Ruch, and L. West, "The promise and problem of critical reflection," in Researching Critical Reflection. Multidisciplinary Perspectives, J. Fook, V. Collington, F. Ross, G. Ruch, and L. West, Eds., Routledge, New York, NY, USA, 2016.

[29] S. D. Brookfield, Teaching for Critical Thinking. Tools and techniques to help students question their assumptions, JosseyBass, San Francisco, Calif, USA, 2012.

[30] K. Illeris, Learning, Studentlitteratur, Lund, Sweden, 2015.

[31] R. Buchanan, "Teacher identity and agency in an era of accountability," Teachers and Teaching: Theory and Practice, vol. 21, no. 6, pp. 700-719, 2015.

[32] A. Manouchehri, "Collegial Interaction and Reflective Practice," Action in Teacher Education, vol. 22, no. 4, pp. 86-97, 2001.

[33] I. S. Horn and J. W. Little, "Attending to problems of practice: Routines and resources for professional learning in teachers' workplace interactions," American Educational Research Journal, vol. 47, no. 1, pp. 181-217, 2010.

[34] K. M. Simoncini, M. Lasen, and S. Rocco, "Professional dialogue, reflective practice and teacher research: Engaging early childhood pre-service teachers in collegial dialogue about curriculum innovation," Australian Journal of Teacher Education, vol. 39, no. 1, Article ID Article 3, 2014.

[35] V. Richardson-Koehler, "Barriers to the Effective Supervision of Student Teaching: A Field Study," Journal of Teacher Education, vol. 39, no. 2, pp. 28-34, 1988.

[36] D. Boud and D. Walker, "Promoting reflection in professional courses: the challenge of context," Studies in Higher Education, vol. 23, no. 2, pp. 191-206, 1998.

[37] M. Nilsson, G. Ejlertsson, I. Andersson, and K. Blomqvist, "Caring as a salutogenic aspect in teachers' lives," Teaching and Teacher Education, vol. 46, pp. 51-61, 2015.

[38] S. M. Carter and M. Little, "Justifying knowledge, justifying method, taking action: Epistemologies, methodologies, and methods in qualitative research," Qualitative Health Research, vol. 17, no. 10, pp. 1316-1328, 2007. 
[39] J. H. Creswell, Research design: Qualitative, quantitative, and mixed methods approaches, Sage, Thousand Oaks, Calif, USA, 2nd edition, 2003.

[40] M. Vaismoradi, H. Turunen, and T. Bondas, "Content analysis and thematic analysis: implications for conducting a qualitative descriptive study," Nursing and Health Sciences, vol. 15, no. 3, pp. 398-405, 2013.

[41] D. Horsburgh, "Evaluation of qualitative research," Journal of Clinical Nursing, vol. 12, no. 2, pp. 307-312, 2003.

[42] A. Cornwall and R. Jewkes, "What is participatory research?" Social Science and Medicine, vol. 41, no. 12, pp. 1667-1676, 1995.

[43] M. Polanyi, T. McIntosh, and A. Kosny, "Understanding and improving the health of workers in the new economy: A call for a participatory dialogue-based approach to work-health research," Critical Public Health, vol. 15, no. 2, pp. 103-119, 2005.

[44] R. Lines, "Influence of participation in strategic change: resistance, organizational commitment and change goal achievement," Journal of Change Management, vol. 4, no. 3, pp. 193-215, 2004.

[45] M. Selkrig and K. Keamy, "Promoting a willingness to wonder: moving from congenial to collegial conversations that encourage deep and critical reflection for teacher educators," Teachers and Teaching: Theory and Practice, vol. 21, no. 4, pp. 421-436, 2015.

[46] G. Gibbs, Learning by Doing: A Guide to Teaching and Learning Methods, Further Education Unit, Oxford Polytechnic, Oxford, UK, 1988.

[47] V. Braun and V. Clarke, "Using thematic analysis in psychology," Qualitative Research in Psychology, vol. 3, no. 2, pp. 77-101, 2006.

[48] V. Clarke and V. Braun, "Teaching thematic analysis," The Psychologist, vol. 26, no. 2, pp. 120-123, 2013.

[49] World Medical Association, "Declaration of Helsinki: ethical principles for medical research involving human subjects," Jama, vol. 310, no. 20, 2191 pages, 2013.

[50] X. Fazio, "Teacher development using group discussion and reflection," Reflective Practice, vol. 10, no. 4, pp. 529-541, 2009.

[51] S. D. Brookfield, "So what exactly is critical about critical reflection?" in Researching Critical Reflection. Multidisciplinary Perspectives, J. Fook, V. Collington, F. Ross, G. Ruch, and L. West, Eds., Routledge, New York, NY, USA, 2016.

[52] L. M. Desimone, "Improving impact studies of teachers' professional development: Toward better conceptualizations and measures," Educational Researcher, vol. 38, no. 3, pp. 181-199, 2009.

[53] H. Borko, "Professional Development and Teacher Learning: Mapping the Terrain," Educational Researcher, vol. 33, no. 8, pp. 3-15, 2004.

[54] J. W. Little, “Teachers' Professional Development in a Climate of Educational Reform," Educational Evaluation and Policy Analysis, vol. 15, no. 2, pp. 129-151, 1993.

[55] Z. Bauman, The Individualized Society, John Wiley \& Sons, 2001.

[56] K. Nielsen, R. Randall, A.-L. Holten, and E. R. González, "Conducting organizational-level occupational health interventions: What works?” Work and Stress, vol. 24, no. 3, pp. 234-259, 2010.

[57] J. Hurrell, J. Barling, E. Kelloway, and M. Frone, “Organizational stress interventions," Handbook of work stress, pp. 623-645, 2005.
[58] M. S. Garet, A. C. Porter, L. Desimone, B. F. Birman, and K. S. Yoon, "What makes professional development effective? Results from a national sample of teachers," American Educational Research Journal, vol. 38, no. 4, pp. 915-945, 2001.

[59] P. Nilsson, I. H. Andersson, G. Ejlertsson, and M. Troein, "Workplace health resources based on sense of coherence theory," International Journal of Workplace Health Management, vol. 5, no. 3, pp. 156-167, 2012.

[60] E. R. Greenglass, R. J. Burke, and R. Konarski, “The impact of social support on the development of burnout in teachers: Examination of a model," Work and Stress, vol. 11, no. 3, pp. 267$278,1997$.

[61] J. Griffith, A. Steptoe, and M. Cropley, "An investigation of coping strategies associated with job stress in teachers," British Journal of Educational Psychology, vol. 69, no. 4, pp. 517-531, 1999.

[62] M. W. Rabow and S. J. McPhee, "Doctoring to heal: Fostering well-being among physicians through personal reflection," Western Journal of Medicine, vol. 174, no. 1, pp. 66-69, 2001.

[63] S. J. Guastello, "Do we really know how well our occupational accident prevention programs work?" Safety Science, vol. 16, no. 3-4, pp. 445-463, 1993.

[64] N. Carr and D. P. Chambers, "Cultural and organisational issues facing online learning communities of teachers," Education and Information Technologies, vol. 11, no. 3-4, pp. 269-282, 2006.

[65] C. Dahl-Jørgensen and P. Ø. Saksvik, "The impact of two organizational interventions on the health of service sector workers," International Journal of Health Services, vol. 35, no. 3, pp. 529-549, 2005.

[66] A. Hargreaves, "Four ages of professionalism and professional learning," Teachers and Teaching: Theory and Practice, vol. 6, no. 2, pp. 151-182, 2000.

[67] P. Docherty, D. Boud, and P. Cressey, "Lessons and issues for practice and development," in Productive reflection at work: Learning for changing organizations, C. Boud, P. Cressey, and P. Docherty, Eds., Routledge, New York, NY, USA, 2006.

[68] B. R. Beatty, “Teachers leading their own professional growth: self-directed reflection and collaboration and changes in perception of self and work in secondary school teachers," Journal of In-Service Education, vol. 26, no. 1, pp. 73-97, 2000.

[69] G. Brante, "Multitasking and synchronous work: Complexities in teacher work," Teaching and Teacher Education, vol. 25, no. 3, pp. 430-436, 2009.

[70] J. A. Supovitz and H. M. Turner, "The effects of professional development on science teaching practices and classroom culture," Journal of Research in Science Teaching, vol. 37, no. 9, pp. 963-980, 2000.

[71] E. M. Skaalvik and S. Skaalvik, "Teacher job satisfaction and motivation to leave the teaching profession: Relations with school context, feeling of belonging, and emotional exhaustion," Teaching and Teacher Education, vol. 27, no. 6, pp. 1029-1038, 2011.

[72] R. Stoecker, "Are Academics Irrelevant?: Roles for Scholars in Participatory Research," American Behavioral Scientist, vol. 42, no. 5, pp. 840-854, 1999.

[73] P. Cressey, D. Boud, and P. Docherty, "The emergence of productive reflection," in Productive reflection at work: Learning for changing organizations, C. Boud, P. Cressey, and P. Docherty, Eds., Routledge, New York, NY, USA, 2006. 
[74] N. Solomon, D. Boud, and D. Rooney, "The in-between: Exposing everyday learning at work," International Journal of Lifelong Education, vol. 25, no. 1, pp. 3-13, 2006.

[75] Y. S. Lincoln and E. G. Guba, Naturalistic Inquiry, Sage Publications, London, UK, 1985. 


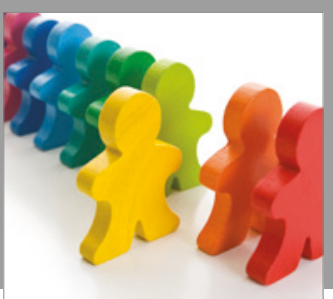

Autism

Research and Treatment
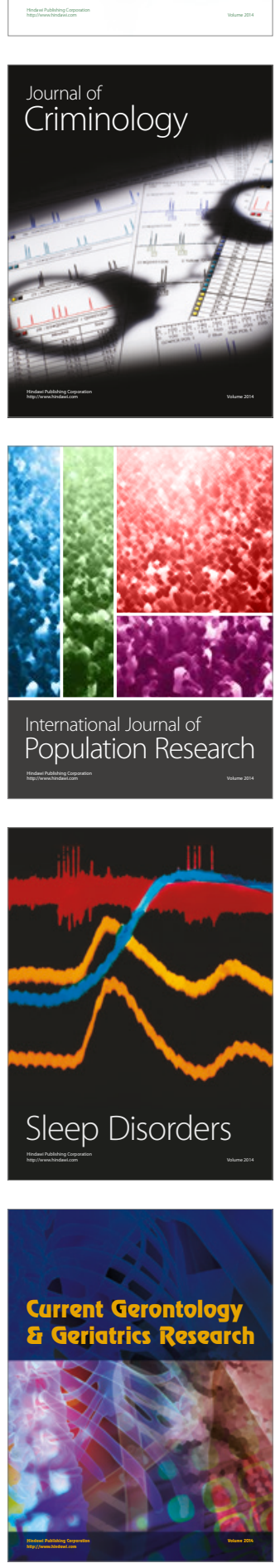

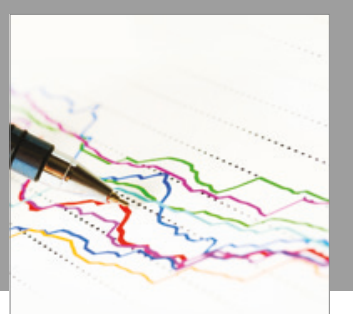

Economics

Research International

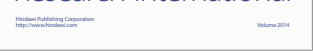

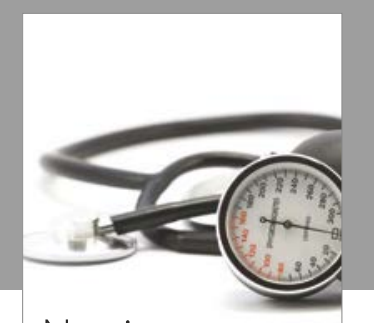

Nursing

Research and Practice

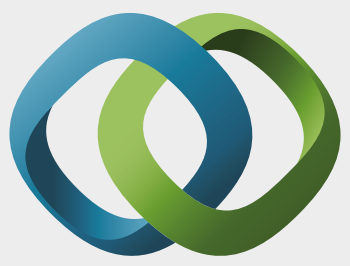

\section{Hindawi}

Submit your manuscripts at

https://www.hindawi.com
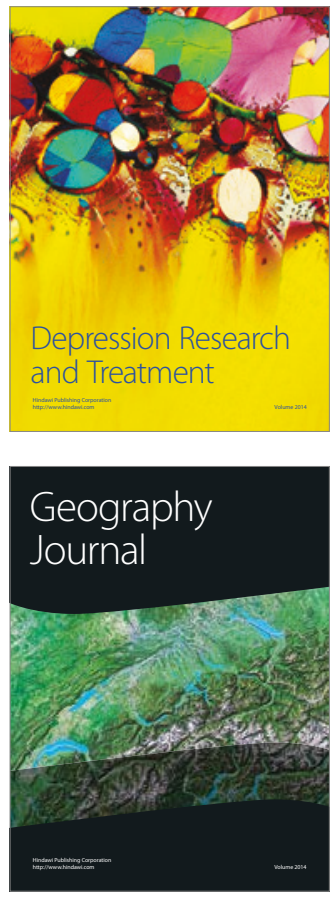
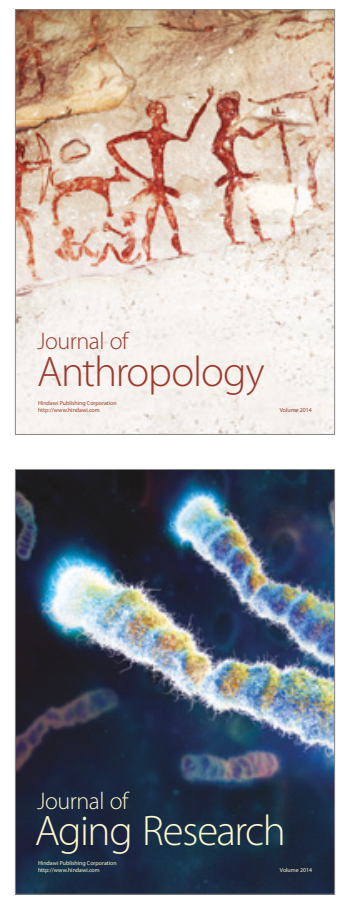
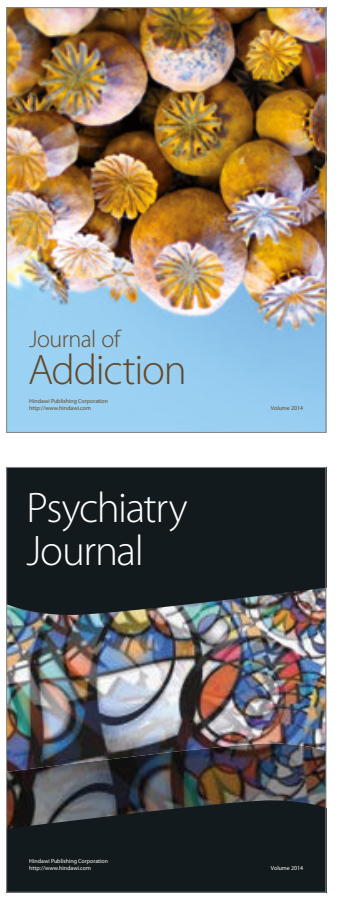

Child Development

Research

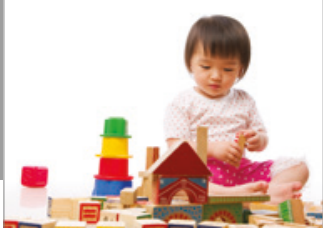

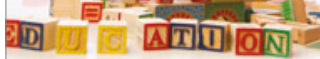
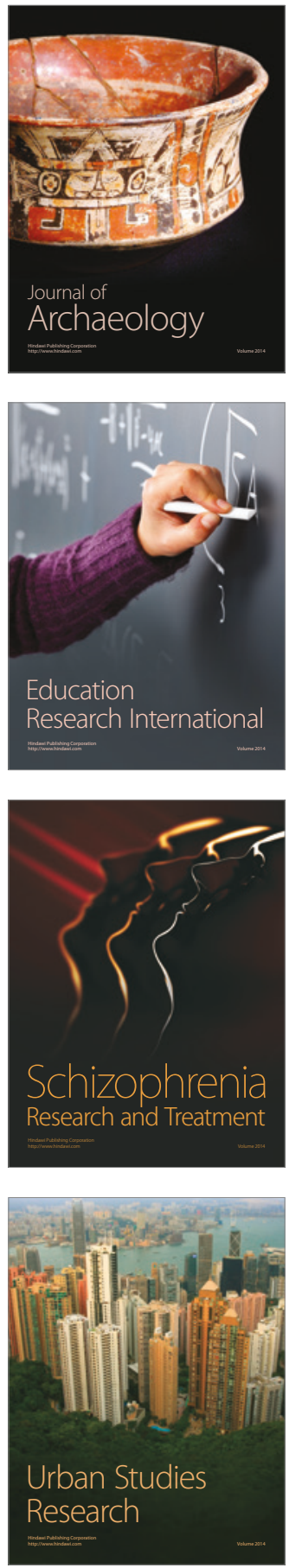